\title{
Familial aggregation of idiopathic dilated cardiomyopathy: clinical features and pedigree analysis in 14 families
}

Elisabetta Zachara, Alida LP Caforio, Gian Piero Carboni, Adalberto Pellegrini, Alessandro Pompili, Giuseppe Del Porto, Antonella Sciarra, Cesare Bosman, Renata Boldrini, Pier Luigi Prati, William J McKenna

\begin{abstract}
Objective-A recent prospective study in patients with dilated cardiomyopathy has reported that the disease is familial in at least $20 \%$ of cases, but the pattern of inheritance could not be ascertained. The presence of an autosomal dominant pattern, such as seen in hypertrophic cardiomyopathy, could make it possible to search for single gene defects with linkage analysis, whereas polygenic inheritance would be consistent with the autoimmune hypothesis. To assess the pattern of inheritance, we retrospectively identified patients with familial disease and assessed their first degree relatives (parents, siblings and children) for dilated cardiomyopathy.
\end{abstract}

Design and patients-The family history of 105 consecutive patients with dilated cardiomyopathy was reviewed and 14 who had at least one first degree relative with documented disease were identified as probands. Their healthy relatives (109) were studied by physical examination, electrocardiography, $\mathbf{M}$ mode and cross sectional echocardiography, and were classified as unequivocally normal or as potential carriers. The potential carriers had abnormal electrocardiography with either at least one echocardiographic measurement of left ventricular cavity dimension or percentage fractional shortening outside 2 SDs of normal values (based on age and body surface area). The potential carriers underwent 24 hour Holter monitoring and maximal treadmill exercise.

Results and conclusion-Twenty three relatives $(21 \%)$ were classified as potential carriers: 12 had an increased left ventricular end diastolic dimension, with reduced percentage fractional shortening in three; 11 had an abnormal electrocardiogram and increased end diastolic dimension, with reduced percentage fractional shortening in five. Such abnormalities were very mild and follow up is necessary to find whether such changes represent early disease. Pedigree analysis was most consistent with polygenic inheritance.

(Br Heart f 1993;69:129-135)
The occurrence of familial dilated cardiomyopathy has been previously underestimated. In a retrospective study $6 \%$ of the patients had familial disease. ${ }^{1}$ In another study familial aggregation was found on the basis of history in $8.7 \%$ of patients who presented at a young age for cardiac transplantation. ${ }^{2}$ Mestroni et al in a study of 165 consecutive patients, in which relatives were evaluated only if disease was suspected, reported that $7 \%$ of cases with dilated cardiomyopathy were familial. ${ }^{3}$ In a recent prospective study of patients whose first degree relatives (parents, siblings, children) were investigated regardless of whether they were suspected of having heart disease the frequency of familial dilated cardiomyopathy was $20 \%{ }^{4}$

Pedigree analysis has produced families with patterns of inheritance consistent with both autosomal dominant, ${ }^{1-13}$ and others with recessive..$^{914}$ Also a large family with $\mathrm{X}$ linked inheritance has been described. ${ }^{15}$ In the prospective study by Michels et al, which is the largest published, segregation analysis of the families was compatible with a model for a single dominant locus with incomplete penetrance, or with polygenic inheritance. ${ }^{4}$

Autoimmune diseases are often familial, although sporadic cases predominate. Such diseases result from the interaction of environmental factors and genetic predisposition and are polygenic in inheritance. ${ }^{16}$ Autoimmunity is involved in $25 \%-35 \%$ of nonfamilial cases with dilated cardiomyopathy, ${ }^{17} 18$ but its potential role in familial disease has not been evaluated; the presence of polygenic inheritance would be consistent with the autoimmune hypothesis. To assess potential patterns of inheritance of familial dilated cardiomyopathy we retrospectively identified, on the basis of history, index cases of familial dilated cardiomyopathy and performed clinical evaluation of their relatives.

\section{Patients and methods}

PATIENTS

Between 1 January 1985 and 31 December 1990, 105 patients with dilated cardiomyopathy were evaluated at our institution. The diagnosis of dilated cardiomyopathy was based on the World Health Organisation criteria with a dilated and poorly contracting left or right ventricle or both in the absence of 
a known cause. ${ }^{19}$ Patients were excluded if there was evidence of: (a) coronary heart disease at selective coronary arteriography; (b) ischaemia during exercise testing; (c) systemic blood pressure $\geqslant 150 / 90 \mathrm{~mm} \mathrm{Hg}$; (d) concomitant systemic or endocrine diseases that are known to cause left ventricular impairment; or (e) excessive alcohol consumption defined as a daily intake of at least eight ounces of spirits or two quarts of beer for the preceding 10 years. ${ }^{20}$ The medical records of all 105 patients with dilated cardiomyopathy were reviewed, also they were questioned to assess whether cases with presumed or confirmed heart disease were present in their families. Further information was obtained from attending physicians or from the hospitals in which the patients' relatives had been admitted. Patients with dilated cardiomyopathy who had at least one first degree relative with documented disease or positive necropsy result, were identified as familial cases (probands). In all probands the assessment included standard 12 lead electrocardiogram, $M$ mode, cross sectional and Doppler echocardiography, 24 hour Holter monitoring, maximal treadmill exercise, right and left heart catheterisation, selective coronary arteriography, right and left ventriculography, and right ventricular endomyocardial biopsy.

\section{RELATIVES}

The study was approved by the local ethics committee and participants gave informed written consent. All probands were asked whether they could invite their first degree relatives to enter the study. A three to four generation pedigree was created. If any first degree relative was found to have dilated cardiomyopathy, their first degree relatives were also contacted and included in the study. For deceased relatives, medical records were reviewed and the diagnosis of dilated cardiomyopathy was based on the same criteria used for the probands, as well as on the necropsy findings.

Patients' relatives with suspected myocardial disease underwent clinical, noninvasive, and where appropriate invasive evaluation. All participating relatives were screened with physical examination, standard 12 lead electrocardiogram, $M$ mode, cross sectional and Doppler echocardiography, and were classified either as unequivocally normal or as potential carriers. The second had abnormal echocardiograms with or without abnormal electrocardiograms. All carriers underwent 24 hour Holter monitoring during normal daily activities, maximal treadmill exercise, and where appropriate cardiac catheterisation and right ventricular endomyocardial biopsy.

\section{ELECTROCARDIOGRAPHIC CRITERIA FOR CARRIERS}

A standard 12 lead electrocardiogram in the relatives was considered to be abnormal if one or more of the following features was pre- sent: left or right atrial enlargement; ${ }^{21}$ rhythm disturbances, particularly atrial fibrillation; conduction disease, including prolongation of the PR interval $(>0 \cdot 20)$ or the QT interval corrected for heart rate $(\mathrm{QTc}=\mathrm{QT} / \mathrm{RR}$ interval); left axis deviation (mean frontal axis $-30^{\circ}$ to $-150^{\circ}$ ) and bundle branch block ${ }^{18}$; and voltage criteria of left ventricular hypertrophy. ${ }^{22}$

\section{ECHOCARDIOGRAPHIC CRITERIA FOR} CARRIERS

Echocardiography was performed with a Hewlett Packard 77020A machine. Measurements of chamber and wall thickness were obtained at mitral valve level on cross sectional guided $M$ mode echocardiograms. Left ventricular end diastolic and end systolic internal dimensions were measured and considered abnormal when they were 2 SDs of established normal values (based on age and body surface area). ${ }^{23}$ These were confirmed in our laboratory in a separate study of 33 normal, healthy subjects (20 male, 13 female, mean (SD) age 26 (15)). Abnormalities of end diastolic dimension were expressed as percentage increase above 2SD for the patient's age, height, and weight, as previously described. ${ }^{23}$ Left ventricular fractional shortening was also calculated; hypokinesis was defined as fractional shortening $<26 \%$ (the normal range in our laboratory is $26 \%$ to $45 \%)$. A cross sectional echocardiogram in the participating relatives was considered to be abnormal if the left ventricular end diastolic or end systolic dimension or fractional shortening were abnormal.

AMBULATORY 24 HOUR HOLTER MONITORING This was performed with a two channel tape recorder (Avionics model 445). A modified inferior lead and a precordial lead corresponding to V4 were monitored. The tapes were analysed on a 660 A Avionics system; ST segment modifications and presence of arrhythmias were verified on electrocardiographic paper strips $(25 \mathrm{~mm} / \mathrm{s})$. Ventricular arrhythmias were classified according to the Lown criteria. ${ }^{24}$

\section{EXERCISE TEST}

Maximal treadmill exercise was performed with a modified Naughton protocol, ${ }^{25}$ according to the American Heart Association recommendations. ${ }^{26} \quad$ Electrocardiographic tracings, heart rate, and systolic blood pressure were measured during exercise and recovery.

\section{CARDIAC CATHETERISATION}

All probands and 10 affected relatives underwent right and left ventriculography and coronary angiography (Judkin's technique). Left ventricular ejection fraction was computed from a $30^{\circ}$ right anterior oblique projection by the area length method. Right ventricular endomyocardial biopsy was also performed with a 502-300 F7 Cordis biotome and an USCI $8591 \mathrm{~F} 8$ Mullins introducer. 
Table 1 Clinical and diagnostic features of probands and surviving relatives with dilated cardiomyopathy

\begin{tabular}{|c|c|c|c|c|c|c|c|c|c|}
\hline Patient & $\begin{array}{l}\text { Pedigree } \\
\text { location }\end{array}$ & Sex/age & $N Y H A$ & $\begin{array}{l}\text { LVEDD } \\
(\mathrm{mm})\end{array}$ & $\% L V E$ & $\% F S$ & $E C G$ & $\begin{array}{l}\text { Lown } \\
\text { grade }\end{array}$ & $\% E F$ \\
\hline 1 & $\mathrm{M}_{1}\left(\mathrm{III}_{1}\right)$ & $M / 48$ & I & 93 & 94 & 11 & LBBB & IVA & 20 \\
\hline 2 & $\mathrm{M}_{1}\left(\mathrm{III}_{4}\right)$ & M/34 & I & 83 & 66 & 14 & LBBB & III & 20 \\
\hline 3 & $\mathrm{R}_{2}\left(\mathrm{II}_{9}\right)$ & M/43 & IV & 87 & 67 & 15 & LBBB & IA & 12 \\
\hline 4 & $\mathrm{~L}_{3}\left(\mathrm{III}_{1}\right)$ & M/39 & IV & 82 & 67 & 15 & LVH & IVB & 23 \\
\hline 5 & $\mathrm{C}_{4}\left(\mathrm{III}_{3}\right)$ & M/51 & III & 67 & 34 & 14 & $\mathrm{LAD}, \mathrm{AVB}, \mathrm{AF}$ & IVA & 19 \\
\hline 6 & $\mathrm{MT}_{5}\left(\mathrm{II}_{2}\right)$ & M/16 & I & 69 & 60 & 15 & LVH & 0 & 20 \\
\hline 7 & $\mathrm{~B}_{6}\left(\mathrm{III}_{1}\right)$ & M/61 & IV & 57 & 36 & 12 & LAFB, AF & IVA & 20 \\
\hline 8 & $\mathrm{~B}_{6}\left(\mathrm{III}_{3}\right)$ & M/57 & IV & 71 & 45 & 9 & LVH & 0 & 25 \\
\hline 9 & $\mathrm{TR}_{7}\left(\mathrm{II}_{4}\right)$ & $\mathrm{F} / 50$ & IV & 52 & 11 & 25 & LBBB & IVA & 20 \\
\hline 10 & $\left.\mathrm{MA}_{8}(\mathrm{II})^{\prime}\right)$ & $\mathrm{M} / 24$ & II & 60 & 18 & 13 & LAFB & IVB & 20 \\
\hline 11 & $\mathrm{~A}_{0}\left(\mathrm{II}_{3}\right)$ & M/54 & II & 70 & 30 & 18 & RBBB & IVB & 37 \\
\hline 12 & $\mathrm{~A}_{0}\left(\mathrm{II}_{5}\right)$ & M/60 & II & 74 & 32 & 16 & RBBB, AVB & IVA & 40 \\
\hline 13 & $\mathrm{Na}_{11}\left(\mathrm{I}_{2}\right)$ & $\mathrm{F} / 59$ & III & 64 & 36 & 22 & LBBB & IVB & 20 \\
\hline 14 & $\mathrm{~N}_{14}\left(\mathrm{II}_{4}\right)$ & M/62 & III & 72 & 44 & 14 & LVH, AVB & IVA & 20 \\
\hline 15 & $\left.\mathrm{~N}_{14} \mathrm{II}_{5}\right)$ & M/64 & II & 68 & 36 & 18 & LBBB, AVB & IVA & 30 \\
\hline 16 & $\mathrm{~S}_{12}\left(\mathrm{I}_{2}\right)$ & $\mathrm{F} / 48$ & IV & 60 & 20 & 12 & LBBB & IVA & 30 \\
\hline 17 & $\mathrm{~V}_{10}\left(\mathrm{II}_{3}\right)$ & $F / 59$ & I & 65 & 38 & 12 & LBBB, AF & IVA & 20 \\
\hline $18^{\star \star}$ & $\mathrm{Bol}_{13}\left(\mathrm{II}_{6}\right)$ & $\mathrm{F} / 64$ & IV & 90 & 91 & 8 & LBBB & III & 20 \\
\hline
\end{tabular}

AVB, atrioventricular block; AF, atrial fibrillation; ECG, electrocardiogram; \%EF, angiographic percentage ejection fraction; $\mathrm{F}$, female; \%FS, percentage fractional shortening; LAD, left axis deviation; LAFB, left anterior fascicular block; LBBB, left bundle branch block; \%LVE, percentage left ventricular enlargement; LVEED, left ventricular end diastolic diameter; LVH, left ventricular hypertrophy; M, male; NYHA, New York Heart Association functional class; ND, not done; RBBB, right bundle branch block; $18^{\star \star}$, two other relatives with dilated cardiomyopathy not seen by us (not shown) are Bol B $_{13}\left(\mathrm{II}_{1}\right)$ and (III,).

\section{Results}

PROBANDS AND RELATIVES WITH DILATED CARDIOMYOPATHY

Fourteen of the 105 patients with dilated cardiomyopathy $(13 \%)$ had at least one first degree relative with documented dilated cardiomyopathy and were identified as probands. There were 23 relatives of the 14 probands who had dilated cardiomyopathy, of whom 19 were dead (13 males, six females, age 43 (23), median 50) and four were alive. All 19 dead relatives had documented disease; in 12 the diagnosis was confirmed at necropsy, whereas in the remaining seven necropsy was not performed.

Table 1 shows the baseline clinical and diagnostic features in the 14 probands and in the additional four living relatives with dilated cardiomyopathy (12 male, six female, age 50 (14)). We did not see two additional relatives with the diagnosis of dilated cardiomyopathy (data included in the pedigree are not shown). At the time of examination four patients $(22 \%)$ were in New York Heart Association (NYHA) functional class I, four $(22 \%)$ in class II, three in class III $(17 \%)$, and seven in class IV (39\%). They had severe left ventricular dilatation (mean percentage increase of the end diastolic dimension $46 \%$

Table 2 Clinical and echocardiographic features of relatives with only an abnormal echocardiogram

\begin{tabular}{|c|c|c|c|c|c|c|}
\hline Case & $\begin{array}{l}\text { Pedigree } \\
\text { location }\end{array}$ & Sexlage & $N Y H A$ & $\begin{array}{l}\text { LVEDD } \\
(\mathrm{mm})\end{array}$ & $\% L V E$ & $\% F S$ \\
\hline 1 & $\mathrm{~L}_{3}\left(\mathrm{III}_{3}\right)$ & M/37 & II & 55 & 8 & 22 \\
\hline 2 & $\mathrm{C}_{4}\left(\mathrm{III}_{3}\right)$ & $\mathrm{M} / 18$ & I & 60 & 15 & 28 \\
\hline 3 & $\mathrm{C}_{4}\left(\mathrm{III}_{7}\right)$ & M/15 & I & 54 & 12 & 37 \\
\hline 4 & $\mathrm{MT}_{5}\left(\mathrm{I}_{2}\right)$ & $F / 38$ & III & 55 & 11 & 25 \\
\hline 5 & $\mathrm{~B}_{6}\left(\mathrm{IV} \mathrm{V}_{6}\right)$ & $M / 24$ & I & 57 & 12 & 33 \\
\hline 6 & $\left.\mathbf{B}_{6}(\mathbf{I V})_{7}\right)$ & $\mathbf{M} / 22$ & I & 58 & 12 & 34 \\
\hline 7 & $B_{6}\left(I V_{9}\right)$ & $M / 15$ & I & 55 & 12 & 25 \\
\hline 8 & $\mathrm{~B}_{6}\left(\mathrm{IV}_{10}\right)$ & $F / 16$ & I & 51 & 6 & 36 \\
\hline 9 & $\mathrm{TR}_{7}\left(\mathrm{III}_{4}\right)$ & $\mathrm{M} / 13$ & I & 55 & 6 & 27 \\
\hline 10 & $\mathrm{~A}_{9}\left(\mathrm{III}_{16}\right)$ & $\mathrm{M} / 14$ & I & 60 & 15 & 30 \\
\hline 11 & $\mathrm{~V}_{10}\left(\mathrm{IIII}_{3}\right)$ & $\mathrm{M} / 36$ & I & 60 & 20 & 33 \\
\hline 12 & $\mathrm{Bol}_{13}\left(\mathrm{IV}_{3}\right)$ & $M / 16$ & I & 60 & 17 & 33 \\
\hline \multicolumn{2}{|c|}{ Mean (SD) } & $23(9)$ & & $57(3)$ & $12(4)$ & $30(5)$ \\
\hline
\end{tabular}

See table 1 for abbreviations.
(23\%) from normal), greatly reduced mean fractional shortening (14\% (4\%)), and angiographic ejection fraction $(23 \%(7 \%))$. The standard electrocardiogram was abnormal in all and 15/18 (82\%) had ventricular arrhythmia (Lown class III or IV) on Holter monitoring. During the follow up six of the 18 patients died: four suddenly (cases $8,10,16$, 18 ), one of heart failure (case 17) and one of acute rejection after orthotopic cardiac transplantantion (case 13) (table 1). Four patients underwent successful cardiac transplantation and are alive (cases 3, 4, 5, 6), one (case 2) has progressed to functional class IV and is on a transplant waiting list.

\section{APPARENTLY HEALTHY RELATIVES}

Of the 124 apparently healthy relatives, 15 had systemic hypertension; they were assessed but were excluded from pedigree analysis. Of the remaining 109 relatives, 103 were symptom free, whereas six experienced effort dyspnoea. Twenty three of the 109 relatives $(21 \%)$ were classified as potential carriers on the basis of an abnormal echocardiogram with or without abnormal electrocardiogram and were subdivided into two groups: subjects with abnormal echocardiogram only ( $n=12$ ) and subjects with both abnormal electrocardiogram and echocardiogram $(n=11)$. Tables 2 and 3 show the individual clinical and diagnostic features in the two groups.

Of the 12 relatives who had only abnormal echocardiograms (10 males, two females, age 23 (9)) 10 patients (83\%) were in NYHA functional class I, one $(8 \%)$ in class II, and one in class III (8\%). Overall they had a mild percentage increase of the left ventricular end diastolic dimension (12\% (4\%) from normal) but the mean value for percentage fractional shortening was within the normal range $30 \%$ (5\%); however, three of these 12 relatives also had reduced percentage fractional shortening $(<26 \%)$.

Of the 11 subjects with both an abnormal electrocardiogram and echocardiogram (seven males, four females, age 38(15) seven 
Table 3 Clinical and diagnostic features of relatives with both an abnormal electrocardiogram and echocardiogram

\begin{tabular}{|c|c|c|c|c|c|c|c|c|c|}
\hline Patient & $\begin{array}{l}\text { Pedigree } \\
\text { location }\end{array}$ & Sexlage & $N Y H A$ & $\begin{array}{l}\text { LVEDD } \\
(\mathrm{mm})\end{array}$ & $\% L V E$ & $\% F S$ & $E C G$ & $\begin{array}{l}\text { Lown } \\
\text { grade }\end{array}$ & $\% E F$ \\
\hline 1 & $M_{1}\left(I V_{1}\right)$ & M/9 & I & 49 & 7 & 29 & RBBB & ND & ND \\
\hline 2 & $\mathrm{R}_{2}\left(\mathrm{II}_{4}\right) \neq$ & $\mathrm{F} / 61$ & III & 52 & 6 & 24 & LAD, LAFB, LVH & IA & 62 \\
\hline 3 & $\mathrm{R}_{2}\left(\mathrm{III}_{6}\right)$ & $M / 28$ & I & 53 & 6 & 32 & LVH & 0 & ND \\
\hline 4 & $\mathrm{~L}_{3}\left(\mathrm{III}_{5}\right)$ & $\mathrm{M} / 33$ & II & 54 & 8 & 22 & $\star$ & IA & ND \\
\hline 5 & $\mathrm{MT}_{5}\left(\mathrm{I}_{1}\right)$ & M/41 & I & 55 & 8 & 33 & $t$ & 0 & ND \\
\hline 6 & $\mathrm{~B}_{6}\left(\mathrm{III}_{4}\right)$ & M/52 & IV & 70 & 40 & 13 & LAE† & III & 60 \\
\hline 7 & $\mathbf{B}_{6}\left(\right.$ III $\left._{7}\right)$ & $\mathrm{M} / 58$ & II & 77 & 64 & 23 & LBBB & 0 & ND \\
\hline 8 & $\mathrm{Na}_{11}\left(\mathrm{II}_{2}\right)$ & $F / 28$ & I & 48 & 2 & 39 & $\star$ & IVA & 60 \\
\hline 9 & $\mathrm{Na}_{11}\left(\mathrm{II}_{1}\right)$ & $\mathbf{F} / 35$ & I & 51 & 6 & 34 & $t$ & IVA & 60 \\
\hline 10 & $S_{12}\left(\mathrm{II}_{1}\right)$ & $\mathrm{F} / 31$ & $\bar{I}$ & 52 & 8 & 22 & LAE & 0 & ND \\
\hline 11 & $\mathrm{Bol}_{13}\left(\mathrm{IIII}_{3}\right)$ & M/39 & I & 55 & 8 & 37 & AVB & 0 & ND \\
\hline \multicolumn{2}{|c|}{ Mean $(S D)$} & $38(15)$ & & $56(9)$ & $15(19)$ & $27(8)$ & & $60(1)$ & \\
\hline
\end{tabular}

${ }^{\star}$ Low amplitude QRS in precordial leads; tnon-specific epolarisation abnormalities; LAE, left atrial enlargement. ‡Coronary angiogram normal. For other abbreviations see table 1.

patients $(60 \%)$ were in NYHA functional class I, two (10\%) in class II, one in class III $(10 \%)$, and one in class IV $(10 \%)$. They had increased left ventricular end diastolic dimension two to $64 \%$, median $8 \%$ from normal) with normal or borderline mean percentage fractional shortening $(27 \%(8 \%) ; 5 / 10(50 \%)$ had left ventricular hypokinesis, and 3/10 $(30 \%)$ had ventricular arrhythmia on Holter monitoring (Lown class III or IV).

The proportion of relatives who had left ventricular end diastolic cavity dimension above normal for their age and body size $(23 / 109,21 \%)$ was significantly higher than that seen among the similarly aged healthy subjects without familial occurrence of dilated cardiomyopathy $(1 / 33,3 \%, \mathrm{p}<0.01)$. The mean percentage fractional shortening was significantly lower in the 23 relatives with enlarged ventricles than in the remaining 86 relatives with normal sized ventricles $(29 \%$ $(6 \%)$ v $35 \%(4 \%) \mathrm{p}<0.05)$. The 23 relatives with enlarged ventricles differed from the other 86 relatives only with respect to sex; 19 of them $(73 \%)$ were male compared with 34 (39\%) among relatives classified as normals $(\mathrm{p}<0.002)$.

\section{PEDIGREE ANALYSIS}

The figures show the pedigrees of all 14 fami-

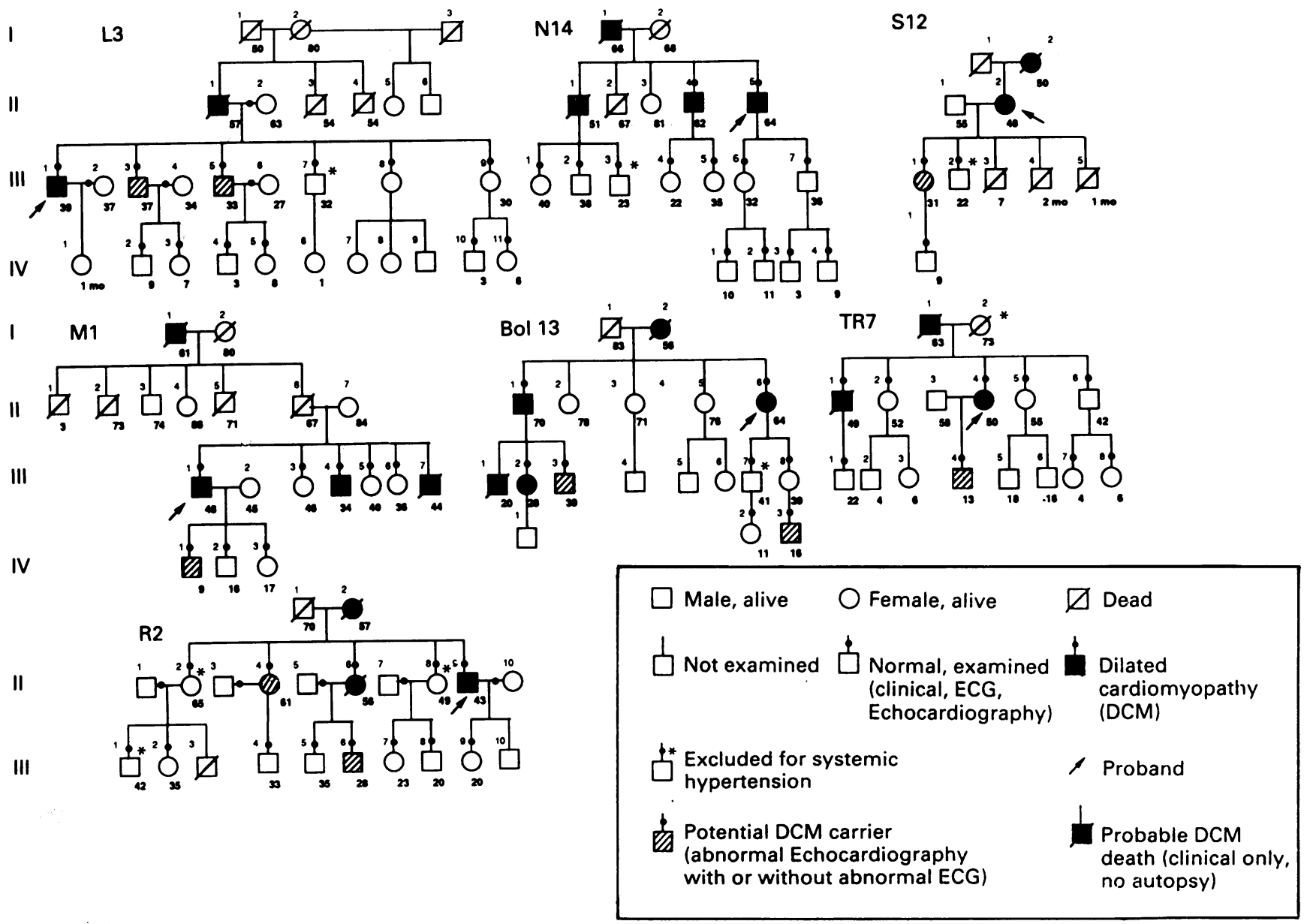

Figure 1 Pedigree of the seven families that show autosomal dominant transmission with incomplete penetrance. 


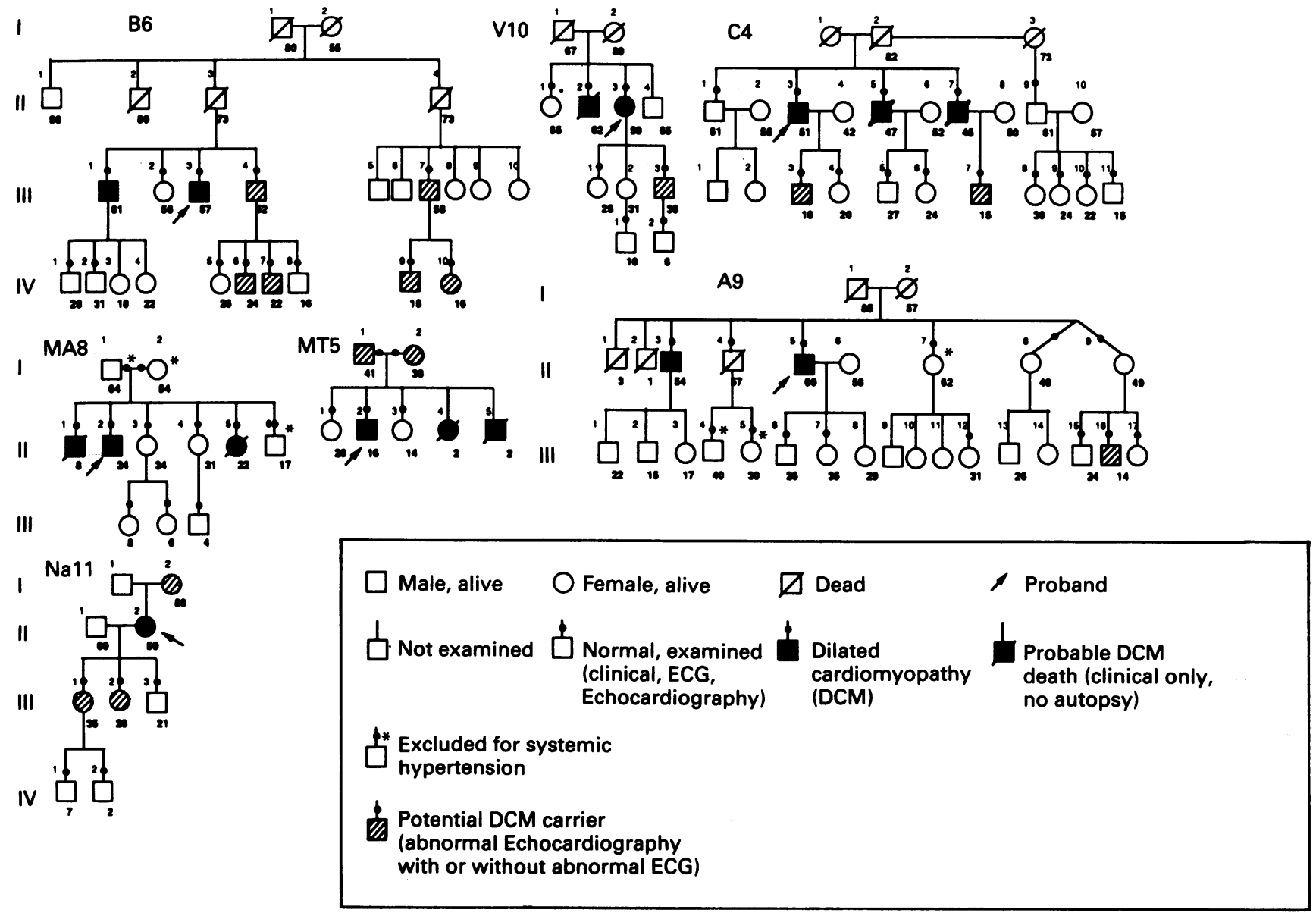

Figure 2 Pedigree of the seven families that show autosomal recessive transmission.

lies. Twenty three of the 109 apparently healthy relatives $(21 \%)$ were classified as potential carriers. When these were included as affected subjects in the analysis of the pedigrees, the pattern of inheritance was compatible with autosomal dominant with incomplete penetrance in all of the families but one (MA8, pedigree shown in fig 2), in which an autosomal recessive mode was suggested.

If the 23 carriers were classified as indeterminate or unaffected, a pattern of inheritance consistent with autosomal dominant transmission with incomplete penetrance was present in seven families (fig 1). In the remaining seven families (fig 2) the pattern of inheritance was compatible with autosomal recessive transmission. This could not be established with certainty because there were no consanguineous marriages.

\section{Discussion}

In this retrospective study we have shown that the frequency of familial disease with overt dilated cardiomyopathy was $13 \%$ based on ascertainment by history. This figure is similar to that reported $(20 \%)$ in a recent prospective series in which all patients' relatives were evaluated, irrespective of positive family history. ${ }^{4}$ Within the 14 families reported in our study we identified a group (21\%) of clinically symptom free relatives who were younger than the probands and who had mildly dilated hearts with or without hypokinesis, or abnormal electrocardiogram and echocardiogram. Fifteen of the 23 apparently healthy relatives with enlarged left ventricles had only increased end diastolic dimension, eight had both increased end diastolic and end systolic dimension with reduced fractional shortening. Although an increase in the end diastolic dimension is known to occur in trained athletes, ${ }^{27}$ this did not apply to any of the relatives with isolated end diastolic enlargement. Our finding of $21 \%$ of relatives with mild abnormalities is in agreement with results of the prospective study by Michels $e t$ $a l$, in which the relatives with similar features who did not undergo catheterisation were classified as indeterminate. ${ }^{4}$

The symptom free relatives with electrocardiographic or echocardiographic abnormalities may represent latent forms of cardiomyopathic involvement and/or different stages of the disease. This would be consistent with the finding of Sugrue et al, who reported, in a population based cohort of patients with dilated cardiomyopathy, a more slowly progressive course than in those referred to tertiary care centres. ${ }^{28}$

An alternative possibility to explain the presence of such abnormalities in our apparently healthy relatives would be that these 
reflect cutoffs in the definition of normality that are too sensitive. Indeed in most of the symptom free relatives the increase in the end diastolic dimension was only slight and it is possible that such minor abnormalities do not represent disease. The same applies to the electrocardiographic findings. Also the accuracy and interobserver variability of echocardiographic measurements, in particular when assessing mild abnormalities, have to be taken into account; thus, only follow up studies will clarify whether the relatives classified as potential carriers in this and in the prospective study by Michels et $a l^{4}$ will eventually develop dilated cardiomyopathy.

Our analysis included only patients with familial dilated cardiomyopathy who had no known causes of left ventricular dysfunction. Relatives were excluded if there was evidence of recognisable causes of myocardial dysfunction, such as hypertension, heavy alcohol intake, diabetes, or pregnancy. A previous work has shown familial aggregation of dilated cardiomyopathy with an autosomal dominant pattern of inheritance in patients who had heavy alcohol intake. ${ }^{10}$ These authors suggested that alcohol might be a factor modifying the course of the disease. Similarly there have been reports of familial peripartum dilated cardiomyopathy, ${ }^{29}$ and of families with the clinical phenotype of dilated cardiomyopathy and pathological findings of myocarditis, in which a defect in immunoregulation was suggested. ${ }^{30}$ These findings are provocative and warrant genetic investigation and family screening both in the idiopathic and secondary forms of dilated cardiomyopathy.

In our study, when the potential carriers were considered to be affected the pattern of inheritance was consistent with autosomal dominant with incomplete penetrance. If these carriers were classified as indeterminate or unaffected, however, there was apparent heterogeneity in the inheritance patterns (autosomal dominant in some families and autosomal recessive in others). This has been found in previous studies ${ }^{1-39}$ and is most consistent with multiple genetic causes being responsible for disease transmission (polygenic inheritance).$^{31}$ Again follow up evaluation of these carriers is needed to firmly establish the modality of inheritance in familial dilated cardiomyopathy. Single or multiple genetic defects could either directly cause the disease or predispose to the development of disease in the presence of environmental triggers. This is particularly interesting because recent evidence, which includes the presence of circulating cardiac autoantibodies, ${ }^{17-18}$ the finding of inappropriate expression on HLA molecules on endomyocardial biopsy tissue $^{32}$ and the association with specific HLA- DR and possibly DQ phenotypes, ${ }^{33}$ supports the hypothesis that dilated cardiomyopathy is an organ specific autoimmune disease, at least in one third of non-familial cases. Dilated cardiomyopathy has analogies with another well recognised autoimmune disease, type I insulin depen- dent diabetes mellitus; in particular there is male predominance and association with the HLA-DR4 phenotype in both conditions. ${ }^{33-34}$ In type I diabetes mellitus there is polygenic inheritance that accounts for only $50 \%$ of disease susceptibility, the remainder being related to environmental causes. ${ }^{34}$

In conclusion family screening of patients with dilated cardiomyopathy has the potential to give new insights into the aetiology, the pathogenesis, and the natural history of dilated cardiomyopathy. The absence of an obvious mode of inheritance in familial dilated cardiomyopathy is most consistent with this condition being not entirely genetic, with polygenic inheritance accounting only in part for disease susceptibility, the remainder being related to environmental factors such as seen in autoimmune conditions.

1 Michels VV, Driscoll DJ, Miller FA Jr. Familial aggregation of idiopathic dilated cardiomyopathy. Am $\mathcal{f}$ Cardiol 1985;55:1232-3.

2 Valatine HA, Hunt SA, Fowler MB, Billingham ME, Schroeder JS. Frequency of familial nature of dilated cardiomyopathy and usefulness of cardiac transplantation in this subset. Am $\mathcal{F}$ Cardiol 1989;63:959-63.

3 Mestroni L, Miani D, Di Lenarda A, Silvestri F, Bussani R, Filippi G, Camerini F. Clinical and pathologic study of familial dilated cardiomyopathy. $\mathrm{Am} f \mathrm{f}$ Cardiol 1990;65:1449-53.

4 Michels VV, Moll PP, Miller FA, Tajik JA, Chu JS, Driscoll DJ, et al. The frequency of familial dilated cardiomyopathy in a series of patients with idiopathic dilated cardiomyopathy. N Engl $₹$ Med 1992;326:77-82.

5 Csanday M, Szasz K. Familial cardiomyopathy. Cardiology 1976;61:122-30.

6 Graber H, Unverferth DV, Baker PB, et al. Evolution of a hereditary cardiac conduction and muscle disorder: a study involving a family with six generations affected. Circulation 1986;74:21-35.

7 Ross RS, Bulkley BH, Hutchins GM, Harshey JS, Jones $\mathrm{RA}$, Kraus $\mathrm{H}$, et al. Idiopathic familial myocardiopathy in three generations: a clinical and pathologic study. $\mathrm{Am}$ Heart f 1978;96:170-9.

8 Barold SS, Linhart JV, Hildner FJ, Rywlin A, Samet P. Familial. cardiomyopathy: a clinical, hemodynamic and angiographic study in one family. Chest 1970:57:141-7.

9 Emanuel R, Withers R, O'Brien K. Dominant and recessive modes of inheritance in idiopathic cardiomyopathy. Lancet 1971;13:1065-7.

10 Gardner RJM, Hanson JW, Ionescu VV, et al. Dominantly inherited dilated cardiomyopathy Am $\mathscr{f}$ Med Genet 1987;27:61-73.

11 Schmidt MA, Michels VV, Edwards WD, Miller FA. Familial dilated cardiomyopathy. Am $\mathcal{F}$ Genet 1988;31: 135-43.

12 Lindvall K, Lundman T, Moller E. Ventricular arrhythmias and left ventricular dysfunction in familial cardiomyopathy. Acta Med Scand 1983;214:135-43

13 Moller P, Lunde P, Hovig T, Nitter-Hauge S. Familial cardiomyopathy. Autosomally, dominantly inherited congestive cardiomyopathy with two cases of septal hypertrophy in one family. Clin Genet 1979;16:233-43.

14 Goldblatt J, Melmed J, Rose G. Autosomal recessive inheritance of idiopathic dilated cardiomyopathy in a Madeira Portuguese kindred. Clin Genet 1987;31: 249-54.

15 Berko BA, Swift M. X-linked dilated cardiomyopathy. $N$ Engl ๆ Med 1987;316:1186-9.

16 Doniach D, Bottazzo GF, eds. Endocrine and other organ-oriented autoimmune disorders. Balliere's Clinical Immunology and Allergy. Vol 1. Ballière Tindall, WB Saunders: London, 1987

17 Caforio ALP, Bonifacio E, Stewart JT, Neglia D, Parodi O, Bottazzo GF, McKenna WJ. Novel organ-specific cardiac autoantibodies in dilated cardiomyopathy. $\mathcal{F} \mathrm{Am}$ Coll Cardiol 1990;15:1527-34.

18 Neumann DA, Burek CL, Baughmann KL, Rose NR, Herskowitz A. Circulating heart-reactive antibodies in patients with myocarditis or cardiomyopathy. $7 \mathrm{Am} \mathrm{Coll}$ Cardiol 1990;16:839-46.

19 Report of the WHO/ISFC task force on definition and classification of cardiomyopathies. Br Heart $\mathcal{F} 1980 ; 44$ : 672-3.

20 Fuster V, Gersh BJ, Giuliani ER, Tajik AJ, Brandenburg RO, Irye RL. The natural history of idiopathic dilated RO, Irye RL. The natural history of idiopathic
cardiomyopathy. Am $₹$ Cardiol $1981 ; 47: 525-31$.

21 Bethesda Conference on Optimal Electrocardiography. Task Force 1: standardization of terminology and interpretation. Am $\mathcal{f}$ Cardiol 1978;41:130-45.

22 Sokolow M, Lyon TP. The ventricular complex in left ventricular hypertrophy as obtained by unipolar precor- 
dial and limb leads. Am Heart $\mathcal{f}$ 1949;37:161-86.

23 Henry WL, Gardin JM, Ware JH. Echocardiographic measurements in normal subjects from infancy to old age. Circulation 1980;62:1054-61

24 Lown B, Wolf $M$. Approach to sudden death from coronary heart disease. Circulation 1971;44:130-5.

25 Naughton JP. The contribution of regular physical activity to the ambulatory care of cardiac patients. Postgrad Med to the ambulatory.

26 Ellestad HH, Bolmquist CG, Naughton JP. Standards for adult exercise testing laboratories. Circulation 1979;58. 421-30.

27 Maron BJ. Structural features of the athlete heart as defined by echocardiography. $f$ Am Coll Cardiol 1986; 7:190-203.

28 Sugrue DD, Codd MB, Melton LJ, Gersh BJ. The natural history of idiopathic dilated cardiomyopathy: a comparison of population based and referred cohorts (abstract). Proceedings of the British Cardiac Society. London: British Cardiac Society, 1989;61:88-9.

29 Voss EG, Reddy CVR, Detrano R, Virmani R, Zabriskie
JB, Fotino M. Familial dilated cardiomyopathy. $A m \mathcal{F}$ Cardiol 1984;54:456-7.

30 O'Connell J, Fowles RE, Robinson JA, Subramanian R, Henkin RE, Gunnar RM. Clinical and pathologic findings of myocarditis in two families with dilated cardiomyopathy. Am Heart $₹$ 1983;107:127-35.

31 Bender JR. Idiopathic dilated cardiomyopathy. An immunologic, genetic, or infectious disease or all of the above? Circulation 1991;83:704-6.

32 Caforio ALP, Stewart JT, Bonifacio E, Burke M, Davies MJ, McKenna WJ, Bottazzo GF. Inappropriate major histocompatibility complex expression on cardiac tissue in dilated cardiomyopathy. Relevance for autoimmunity? Fournal of Autoimmunity 1990;3:187-200.

33 Carlquist JF, Menlove RL, Murray MB, O'Connell JB, Anderson JF. HLA class II (DR and DQ) antigen associations in idiopathic dilated cardiomyopathy. Validation study and meta-analysis of published HLA association studies. Circulation 1991;83:515-22.

34 Baekkeskov S, Hansen B. Human diabetes. Curr Topics Microbiol Immunol 1990;164:1-193. 